\title{
Laptops and mobile phones at self-study time: Examining the mechanism behind interruption and multitasking
}

\author{
Liping Deng \\ Hong Kong Baptist University
}

\begin{abstract}
This study examines university students' multitasking with computers and mobile phones in an authentic self-study context, with the primary focus being on off-task multitasking and interruption as precursor to multitasking. The study drew on interviews, observation, and video-stimulated recall to reveal the triggers for and processes of multitasking. It has identified pop-up notifications as the main external interruption and task completion as well as boredom as the internal sources of interruption. The results also pinpointed task as an important dimension associated with both internal and external interruptions. A framework of multitasking triggers was constructed encompassing user, technology and task. The implications of the findings for students, teachers and researchers are also discussed.
\end{abstract}

Implications for practice or policy:

- Students should ward off the disruptive influence of notifications on phones during study time.

- Students should have a better sense of the optimal timing for switching attention.

- Teachers should strive to provide meaningful, relevant and personalized learning tasks.

Keywords: multitasking, self-study, mobile phone, Informal learning, Interruption

\section{Introduction}

University students who have grown up in the digital world are used to the life that is always-on and constantly connected. On the university campus, multitasking with digital technologies has become the norm in formal (Hembrooke \& Gay, 2003; Kraushaar \& Novak, 2010) and informal learning settings (Judd, 2015; Rosen, Carrier, \& Cheever, 2013). Although multitasking is not a new phenomenon, its frequency has increased markedly due to the pervasiveness and ubiquity of digital technologies (Wood \& Zivcakova, 2015). Against this backdrop, laptops and phones are shown to be the major source of distraction for students (Hembrooke \& Gay, 2003; Rosen et al., 2013); hence there has been increasing concern over the disruptive force of computers and smart phones and their effect on student memory, concentration, and learning performance (e.g., Junco \& Cotten, 2012; Patterson, 2017; Ravizza, Uitvlugt, \& Fenn, 2017; Wood et al., 2012). However, our understanding of the nature of interruption from mobile phones and computers and the process of the ensuing task switching is far from conclusive. Examination of multitasking has focused on either computer-based multitasking (e.g., Benbunan-Fich, Adler, \& Mavlanova, 2011; Jin \& Dabbish, 2009) or multitasking via mobile phones (e.g., David, Kim, Brickman, Ran, \& Curtis, 2015). To the best of the researcher's knowledge, there has been no study that examines multitasking with computer and mobile phone simultaneously in educational settings.

Many studies (e.g., Dix, Ramduny-Ellis, \& Wilkinson, 2004; Pashler, 1994) have interpreted multitasking as task switching. This study has mainly focused on switches from primary learning tasks to activities not related to learning in self-study settings, with a particular interest in interruptions as triggers for task switches (see Dix et al., 2004). In this regard, the interruption was regarded as the precursor to task switching, not as equivalent to switching itself. Three research questions were formed to guide the investigation:

1. How do university students multitask with mobile phones and laptops during self-study time?

2. What are the major sources of interruptions that trigger task switching during self-study time?

3. How do students respond to the external interruptions?

The findings of the study can inform researchers and practitioners on how to decipher the complex phenomenon of multitasking including the driving forces behind students' multitasking behaviours and strategies students use, if any, to ward off or mitigate against the disruptive effects of the devices. A set of 
practical guidelines and recommendations generated can assist teachers and students to cope with the disruptive impact of digital technologies.

\section{Literature review}

\section{Conceptualisation of interruption and multitasking}

Multitasking is usually conceptualised either as dual tasking or rapid attention switching (Wood \& Zivcakova, 2015). Dual tasking refers to doing two or more things at the same time (David et al., 2015), yet some scholars argued that such simultaneous processing was impossible for certain tasks due to cognitive bottle-neck (Pashler, 1994). Salvucci and Taatgen (2010) sought to create a unified theory of multitasking through mapping out different types of multitasking according to the rate of task switching. Concurrent multitasking resides at one end of the multitasking continuum with each task progressing almost simultaneously, while sequential multitasking is situated at the other end, with task switching taking place at a much slower rate.

Many scholars have perceived multitasking as task interference or interruption (Gazzaley \& Rosen, 2016), as it involves putting an ongoing primary task on hold while attending to a new one. Kraushaar and Novak (2010) are among a handful of researchers who have recognised the dual effects of multitasking. They differentiated between productive and distractive multitasking in a learning context depending on the relatedness to a primary learning task. Productive multitasking referred to working on tasks or activities directly related to a primary task, while disruptive multitasking involved engagement with activities unrelated to learning. The current study uses the terms on-task and off-task to distinguish between these two types of multitasking behaviours. The main focus is put on off-task multitasking - that is, switching from a primary learning task before completion to an unacademic task via computer or mobile phone.

\section{Internal drive for multitasking}

In a general sense, task switching can be triggered internally and externally. Task switching can be selfinitiated or triggered by external notifications or environmental cues (Adler \& Benbunan-Fich, 2013; Miyata \& Norman, 1986; Walter, Dunsmuir, \& Westbrook, 2015). Jin and Dabbish (2009) used the term "self-interruption" to describe a "self-initiated switch away from a task prior to its completion" (p. 1799). Work interrupted internally is shown to take longer to resume, which implies that such interruptions might be more problematic and disruptive than other types (Mark, Gonzalez, \& Harris, 2005). The literature has identified a set of self-related factors such as habit, attitude, and characteristics that contribute to multitasking behaviours. Aagaard (2015) and Wang and Tchernev (2012) regarded multitasking with technologies as habitual and impulsive. Jin and Dabbish (2009) identified seven types of self-interruption scenarios, among which routines (developed out of habit) were the most frequently observed selfinterruption. Similarly, Qian and Li (2017) identified the level of technology dependency as a significant predictor of student multitasking with electronic devices during class time. Ravizza et al. (2017) queried why students kept using laptops for nonacademic purposes despite being aware of the negative effects of such behaviour and suggested that the compulsive nature of multitasking behaviour might be the best explanation.

Furthermore, it has been proposed that multitasking arises out of psychological and social needs (Jeong \& Fishbein, 2007). It has been observed that when people are in a negative mode - for example, feeling frustrated, stressed, or mentally tired - they are more inclined to multitask (Adler \& Benbunan-Fich, 2013; Calderwood, Ackerman, \& Conklin, 2014; Qian \& Li, 2017). Multitasking with technologies can function as a valuable channel for relaxation (Wang \& Tchernev, 2012) and relieving stress (Zhang \& Zhang, 2012). In a sense, the psychological and/or emotional states of students in a learning context are closely tied to their learning tasks and motivation. Students were less likely to engage in nonacademic Internet use when they were motivated to perform well (Calderwood et al., 2014) or highly interested in course content (Ravizza et al., 2017). In the same vein, Payne, Duggan, and Neth (2007) considered that the sense of reward played an important role in keeping people on task. Conversely, the perception of primary tasks as being undesirable, demanding, boring, or frustrating could induce students to turn away from them (Aagaard, 2015; Jin \& Dabbish, 2009). 


\section{External drive for multitasking}

Environmental cues are often deemed the common triggers for certain action(s) to take place (Dix et al., 2004). A collection of related studies has indicated that the characteristics and features of technological tools might prompt multitasking behaviours. For example, the convenient access and ubiquitous availability of web-based tools become a strong stimulant for multitasking (Aagaard, 2015).

There is a line of scholarly work in human-computer interaction that centers on notification systems as external interruptions. Notifications can be defined as an "information alert that informs the user of a system event or update" (Paul, Komlodi, \& Lutters, 2015, p. 20). It is argued that these notifications are innately interruptive, since they are designed to divert people's attention (Benbunan-Fich et al., 2011). However, some scholars maintained that notifications could be conducive to managing tasks and might reduce anxiety over the status of systems (Paul et al., 2015). There are system-related issues other than alert notifications that can evoke multitasking. For example, Jin and Dabbish (2009) noted that when users needed to wait for software to load, they tended to switch attention to different tasks out of desire to make best use of time or increase productivity.

Another line of scholarly work centres on the process of interruption and task switching. Trafton, Altmann, Brock, and Mintz (2003) depicted a timeline of task interruption and task resumption and observed that switches between tasks were not straightforward and direct. They identified two lags: (1) an interruption lag between the alert and start of a secondary task; and (2) a resumption lag between dropping the secondary task and beginning the primary task. Similarly, Iqbal and Horvitz (2007) added a temporal dimension to external interruption by advancing a model of interruption lifecycle which went through the phases of focused attention, alert arrival, diversion, and resumption of original task. They also distinguished immediate and delayed responses to alerts with the former indicating alert-driven interruptions and the latter involving internal deliberation.

Studies to date have identified a number of internal and external drivers for multitasking. However, most studies on interruption have focused on the effects of interruption on performance using experimental research design (e.g., Bailey \& Konstan, 2006; Calderwood, Green, Joy-Gaba, \& Moloney, 2016; Lin, Mills, \& Ifenthaler, 2016; Speier, Vessey, \& Valacich, 2003), which confines our understanding in relation to how students multitask in an authentic learning context (Judd, 2013; Lin, Cranton, \& Lee, 2014). Another problem associated with quantitative approaches is that they have led to a quite fragmented rather than holistic picture of the phenomenon of multitasking. For instance, Zhang's (2015) study only focused on the effects of user characteristics on multitasking behaviours. The study conducted by Gerow, Galluch, and Thatcher (2010) lost sight of technology as an external trigger for multitasking. This study aims to address this by determining not only the internal and external sources of interruption, but also the interplay among them.

\section{Methods}

\section{Participants and context}

This study adopts a qualitative research design to explore students' multitasking with mobile phones and computers in authentic self-study sessions. It was contextualised in a medium-sized comprehensive university in Hong Kong with the view to recruiting student participants from a variety of disciplines. The study involved 16 students selected through purposive and snowball sampling techniques with criteria including different disciplines, year levels, and varying levels of engagement with digital technologies. The participants were invited to recommend classmates or friends fitting certain profiles (e.g., male students with high engagement in multitasking with phone). The participants included 10 females and 6 males from the faculties of communication (4), arts (2), social science (5), business (2), Chinese medicine (2), and science (1). They were mostly undergraduates in Year 2, 3, or 4, while three were from the postgraduate diploma program (Year 5).

\section{Data collection}

The study acquired ethical approval before the data collection. Each student was first invited to attend a semi-structured interview that aimed to elicit: (1) self-study habits, (2) experience with computer and 
mobile phone, (3) multitasking habits during study time, and (4) use of technologies for learning. The individual interviews lasted about 1 hour, and were recorded and later transcribed. Additionally, observation and video-stimulated recall were conducted to collect rich data on students' multitasking behaviours. Many studies on multitasking depend on participants to self-report their multitasking behaviours. Such simultaneous reporting during the process (e.g., Benbunan-Fich et al., 2011) would risk disrupting the normal work flow. To address these problems, this study utilised video-stimulated recall (see Lyle, 2003) that combined the objective observation of behaviours with subjective self-reporting on the reasons behind them.

Eleven students took part in the observation and were invited to bring their laptops and mobile phones to a lab where they were asked to work on their schoolwork as normally as possible for about 1 hour. The lab was equipped with a computer and video camera that captured the screens of their devices as well as their multitasking behaviours. The video recording allowed the researcher and students to analyse the multitasking behaviours later on. To minimise observer effects, the researcher observed through Skype in another room. During the observation, the researcher systematically recorded timestamped information on switches involving computer and mobile phone. Immediately after the observation, each student joined the researcher in reviewing the video and examining each instance of device switching. They were prompted to reflect on the tasks or activities underway, the triggers for task switches, and the decision-making processes of remaining on task or switching. Typical questions included:

- What made you stop working and pick up the phone at that point?

- What apps did you use? Are they related to learning?

- When you chose to ignore a phone notification, what was the reason?

Through the interview, a matrix of multitasking behaviours adapted from Benbunan-Fich et al. (2011) was filled out, with the following information recorded in relation to each device switch: start time, device involved, relatedness to learning, associated activities, and trigger for switching. The length of the afterobservation interviews varied from 5 to 38 minutes due to the varying levels of the students' multitasking behaviours. The interviews were also recorded and transcribed for later analysis.

\section{Data analysis}

The interview data was analysed using NVivo following two rounds of coding (descriptive followed by thematic). The observation video data was then coded to reveal in detail students' multitasking behaviours and the mechanisms behind interruption and multitasking. Firstly, the video data was dissected into events defined as continuous use of a device (González \& Mark, 2004) and the start and end time of each event were coded. In conjunction with the interview and observation report, each device switching behaviour was scrutinised to determine its relatedness to learning, specific behaviours involved, and the triggers for multitasking. Afterwards, the total number of switches, frequencies of on-task and off-task multitasking and time spent on devices were calculated. The observation data was also triangulated with interview data.

\section{Results}

\section{Multitasking behaviour}

To provide some descriptive and baseline data on students' multitasking behaviour during self-study sessions, the observation data was coded to reveal the time spent off-task via phone and laptop (Table 1). During the observation, only two students fully concentrated on learning tasks. The other nine varied in the time spent off-task, ranging from 2 to 20 minutes during a study session of approximately 60 minutes. The heaviest multitaskers in the study (S3 and S9) spent around one third of the study time on off-task activities. When looking closely into what type of off-task activities they were engaged in, the data indicated that instant messenger tools such as Whatsapp and SnapChat were the most common off-task activities $(73 \%)$, followed by music (12\%) and social networking sites (SNSs) (7\%). 
Table 1

Time spent off-task on phone and laptop (in minutes)

\begin{tabular}{lrrrrr}
\hline ID & $\begin{array}{c}\text { Total } \\
\text { time }\end{array}$ & study & Phone usage & $\begin{array}{c}\text { Off-task on } \\
\text { phone }\end{array}$ & $\begin{array}{c}\text { Laptop usage } \\
\text { Off-task on } \\
\text { laptop }\end{array}$ \\
\hline S1 & 55 & 4 & $4(100 \%)$ & 46 & $0(0 \%)$ \\
S2 & 60 & 2 & $0(0 \%)$ & 57 & $0(0 \%)$ \\
S3 & 63 & 22 & $19(86 \%)$ & 19 & $0(0 \%)$ \\
S4 & 60 & 8 & $1(13 \%)$ & 47 & $2(4 \%)$ \\
S5 & 64 & 3 & $3(100 \%)$ & 20 & $2(10 \%)$ \\
S6 & 56 & 3 & $3(100 \%)$ & 54 & $7(13 \%)$ \\
S7 & 62 & 1 & $1(100 \%)$ & 58 & $5(9 \%)$ \\
S8 & 63 & 11 & $11(100 \%)$ & 5 & $0(0 \%)$ \\
S9 & 52 & 16 & $15(94 \%)$ & 12 & $1(8 \%)$ \\
S10 & 62 & 0 & $0(0 \%)$ & 61 & $0(0 \%)$ \\
S11 & 45 & 0 & $0(0 \%)$ & 24 & $1(4 \%)$ \\
\hline
\end{tabular}

One salient pattern concerning device usage is that mobile phones were mostly used for off-task purposes and laptops for learning-related purposes. With the exception of S4, all students employed mobile phones primarily for activities unrelated to learning. By contrast, laptops were employed mainly for academic purposes, with five students devoting laptops to study only. The other four spent less than $10 \%$ of their laptop time on off-task activities. S5 spent only 2 minutes at the outset of the learning session responding to messages. This pattern of starting a learning session with checking devices and "getting messages out of way" was observed in all participants who engaged in off-task behaviours. S6 was the only student to use their laptop more extensively for off-task multitasking, the reason being she responded to WhatsApp messages mainly on her laptop.

This pattern of designating devices for different purposes was also confirmed by the interview data. A clear majority of respondents (e.g., S3, 4, 15, 16) stated that their use of laptops was mostly dedicated to academic purposes while their phones were more for personal, social and entertainment purposes. S3 is one of those who drew a clear line between the two, stating: "I defined the purposes of these two tools. When I need to work, I turn on my laptop; when I want to play, I pick up my phone.” This being so, there were burgeoning signs of students using phones for academic work. With the pervasive availability of cloud-based services, the students commented that they could easily access and even work on their assignment "on the move" (S3). S6 recalled that she once worked on an assignment entirely on her phone and commented that "there is a trend that more students are using mobile phone to do homework because it's so convenient".

The other theme that emerged from the interviews is that multitasking behaviours are not static, but fluid. The students unanimously remarked that their level of multitasking was changeable, depending mainly on the nature of learning tasks at hand. S2 commented that she tended to be more concentrated when working on the tasks she had most interest. S3 described two types of learning modes: "When I am really concentrating, nothing can influence me, even messages. But if I am not concentrating so hard, or I am about to finish my homework, I keep using the phone." She described herself as a "deadline fighter" and estimated that while she normally spent at least half her home study time on activities not related to learning, she could "keep working for hours without checking my phone" on the night before a deadline. These indicate that the importance and urgency of learning tasks, to a great extent, mediated the participants' multitasking behaviour.

\section{Source of interruption}

Based on interview and observation data, the current study scrutinised both internal and external sources of interruption that triggered off-task multitasking. Through analysis, four types of triggers were identified inductively: notification and idle time as external triggers; boredom and task completion as internal triggers. Table 2 shows the coding results of the sources of interruption for the total 98 off-task multitasking instances coded. The most striking initial observation from Table 2 is that the students' wide diversity in off-task multitasking with such events ranging from 2 to 26 times. Two students (S2 and S10) are excluded 
since they were not engaged in any off-task multitasking behaviours. Pop-up notifications on phones was found to be the major external interruption triggering $59 \%$ of off-task multitasking. The second most prevalent trigger accounting for $20 \%$ of off-task multitasking was task completion. Only $11 \%$ of switching is attributable to boredom and a similar percentage $(8 \%)$ is noted for external interruptions stemming from waiting or idle time. That is to say, when students needed to wait for software or apps to load, they tended to switch to other activities.

Table 2

Analysis results of the triggers for task switches

\begin{tabular}{lrrrrr}
\hline \multicolumn{1}{c}{ ID } & $\begin{array}{c}\text { Off-task multitasking } \\
\text { events }\end{array}$ & $\begin{array}{c}\text { External: } \\
\text { Notification }\end{array}$ & $\begin{array}{c}\text { External: } \\
\text { Idle time }\end{array}$ & $\begin{array}{c}\text { Internal: } \\
\text { Bored }\end{array}$ & $\begin{array}{c}\text { Internal: Task } \\
\text { completion }\end{array}$ \\
\hline S1 & 2 & 0 & 0 & 0 & 2 \\
S3 & 7 & 2 & 1 & 2 & 1 \\
S4 & 11 & 3 & 5 & 3 & 0 \\
S5 & 4 & 1 & 0 & 0 & 3 \\
S6 & 26 & 23 & 1 & 1 & 1 \\
S7 & 6 & 5 & 0 & 0 & 1 \\
S8 & 19 & 14 & 0 & 1 & 4 \\
S9 & 20 & 8 & 1 & 2 & 8 \\
S11 & 3 & 1 & 0 & 2 & 0 \\
Total & 98 & $58(59 \%)$ & $8(8 \%)$ & $11(11 \%)$ & $21(22 \%)$ \\
\hline
\end{tabular}

Internal source of interruption

The interviews provided more revealing data on the triggers for multitasking. Several acknowledged that they were used to constant phone checking in their daily lives. S6 went so far as to describe her behaviour of phone checking as compulsive, stating that she felt the need to "be constantly connected". She remarked: "Sometimes, I might not have a specific purpose like checking message. I put my hand on my phone just because my hand itches." S9 and S13 echoed this by acknowledging phone checking as an entrenched habit. S13 commented: "Once I haven't touched my phone for a while, I feel an urge to check it."

Interruptions initiated internally are often associated with the learning tasks at hand. Firstly, low interest, boredom and frustration were commonly mentioned feelings associated with learning tasks during which the students switched to unrelated activities. Referring to her feelings and thoughts when facing an assignment, S1 stated: "Since I didn't want to do it (assignment), I checked the messages first. It helped me relax and escape from it." S14 shared the similar feeling: "I chose to relax first. I messaged my friends telling them how bad I felt about it (assignment)."

Secondly, students tended to switch tasks when they felt stuck and several such instances were noted in the observation (e.g., S1, S4, S6, S7, S10, S12). While S3 was being observed, there was an occasion on which she switched to off task multitasking when she "felt confused and didn't know how to go on". When the learning task was too challenging, the students felt frustrated. As S7 put it: "When I got really frustrated, I told myself, that's it, then switched to my phone." Conversely, easy tasks could also prompt off-task multitasking. For instance, S5 confessed that she tended to use her phone more frequently when working on easy tasks, since she felt she had "a lot of time" in reserve. S3 shared the same view by saying that she tended to procrastinate and multitask when she was quite sure she could accomplish a certain task. She elaborated thus: "The more I feel certain about a task, the more likely I am to wait until the last minute (to start)." When reflecting on such behaviour, S12 commented: "It seems that I have more RAM to do other things."

Thirdly, the students usually turned to their phones after finishing a task or sub-task, but their perception on what constituted such "breakable moments" varied. S3 noted that she tended to take a break when she accomplished a small step by saying: "Whenever I have found a piece of information I need, then put the information into my document, I will take a break." S10, on the other hand, described that she would not take break until she "got a big part done". Interestingly, sometimes the students switched to their phones when they came up with solutions or when they sensed the task completion was imminent. S9 is a case in 
point. Recalling why he switched tasks he stated: "After I read the question, I know how to do it. But I don't want to do it immediately." He admitted that he had this habit of "holding the ideas in my mind while I do other things". In her interview, S15 described a similar tendency of checking her phone towards the end of the learning session by stating: "Sometimes when I only have a little bit of work left, I start to feel relaxed. I know I can finish very quickly. I feel it's OK to check my phone at this point."

\section{External source of interruption}

First, the students were asked where they put their phones while studying since the location of the phone determined the extent and manner of their exposure to notification interruption. It was usual for the students to keep their phone in close vicinity. Among the 16 students in the study, 6 had their phone monitors covered or flipped facing down, while the others had their phones within reach and facing up. S5 was one of those with the phone flipped face down, the strategy being to avoid "checking the phone whenever notification comes in". External sources of interruption comprised mainly of notifications from both computers and mobile phones. Forms of alert and notification varied in degree of obtrusiveness and ranged from small lights to popup notifications and even audio alarms. In the interviews, the respondents were also prompted to identify the biggest distraction from their self-study and the majority pinpointed phone and in particular messages. They had several apps on their phones that would push notifications whenever new content came in. Without exception, the students in the study referred to WhatsApp, the main instant messaging (IM) tool in Hong Kong, as the top source of notification. Other popular SNSs such as Facebook, Instagram and SnapChat also have notifications.

Although computers are perceived mainly as a learning tool, they are not immune to notifications. Some students (e.g., S6, S7) had installed WhatsApp on their computers, and received screen notifications of new messages. However, many students deemed computer notifications less distracting than those from mobile phones. The following comment from S6 indicated a possible reason for this: "When the dim monitor of the phone lights up, it draws attention to itself immediately, while the laptop monitor is always on, thus the pop-up message is less eye-catching." In echo with this, S8 remarked: "Since I already have a lot of windows open on the laptop, the popups are not so noticeable."

With the triggers for each multitasking event identified, efforts were made to compare internally triggered and externally triggered multitasking behaviours. One interesting finding from the eight students who were influenced by both internal and external triggers was that self-initiated off-task multitasking instances were longer than those triggered by notifications (Table 3). In other words, when students felt bored or upon task completion (internal triggers for multitasking), they tended to spend longer time on activities not related to learning. On the other hand, off-tasking multitasking triggered by external notifications or system tended to take less time.

Table 3

\begin{tabular}{ccc}
\multicolumn{2}{c}{ Average time on off-task multitasking triggered internally and externally } \\
\cline { 1 - 2 } ID & $\begin{array}{c}\text { Self-initiated off- } \\
\text { tasking } \\
\text { multitasking } \\
\text { time }\end{array}$ & $\begin{array}{c}\text { Off-task } \\
\text { multitasking } \\
\text { triggered } \\
\text { externally }\end{array}$ \\
\hline S3 & $6: 10$ & $0: 16$ \\
S4 & $0: 10$ & $0: 08$ \\
S5 & $1: 32$ & $0: 19$ \\
S6 & $0: 28$ & $0: 16$ \\
S7 & $0: 10$ & $0: 37$ \\
S8 & $0: 57$ & $0: 29$ \\
S9 & $1: 20$ & $0: 27$ \\
S1 & $0: 28$ & $0: 10$ \\
\hline
\end{tabular}




\section{Responses to external interruptions}

Through analysing the interview and observation data, students were found to exhibit three different responses to external interruption: (1) unaware or ignore, (2) preview or read message only, and (3) respond to message. Learning tasks also play a role in mediating students' responses to external interruption. First, $35 \%$ of notifications were ignored or did not come to student attention. As S3 described it: "When I was in a state of concentration, I ignored the notifications, even though I sensed the monitor lights up." S6 was the most active in IM and she received 45 notifications during the observation period, of which she ignored half (22). Reflecting on why she ignored incoming messages, she stated: "I was trying to put the thoughts in my mind into words. When I am outputting I don't want to interrupt it." However, while the participants appeared to ignore a notification, their minds might wander. S6 alluded to this in her following comment: "While I was typing the assignment, I couldn't help wondering whether they (her friends) were talking about something interesting. I really wanted to check my phone. But I told myself I should finish this paragraph."

Another interesting observation from the data is that students had different reactions when lot of notifications kept rolling in, signaling continuous conversations in progress. S6 felt a mounting urge to check messages as she worried that "I couldn't catch up with all the messages". S4's response, on the other hand, was completely different. When bombarded by notifications, he chose to ignore them as he explained: "I know I will spend a lot of time reading those messages. I prefer to finish my work, then wait for the exchanges to quiet down - then I can read through all the conversations."

Furthermore, $27 \%$ of time, students previewed or read notifications or messages. S6 described previewing as a good way to ease her itch of "wanting to know who sent messages and whether it's important". Often students moved on to activate the phone and read the full messages. Several students (e.g., S12, S8, S5, S7) acknowledged that they habitually checking the message whenever the notification kicked in. S5 described reactive behaviour, stating that "whenever my phone lights up, my eyes turn to it". The process of activating the phone and reading the full message could be very brief.

After reading messages in full, the students proceeded to respond by answering them in $37 \%$ of occasions. As S5 stated: "When I saw the phone light up, I couldn't help to check it. When I checked it, I couldn't help responding to the messages." There are two different scenarios of response: delayed and immediate response. When asked when they would choose to respond to messages immediately after checking, the students unanimously advised that it depended on the sender and nature of the message, and their level of engagement with the learning task. Often, they felt obliged to respond immediately to those with "close and intimate relationships" (S1, S2, S6). The other type of messages that many students prioritised was those related to learning. For example, WhatsApp messages about group projects were often considered critical, and thus "required immediate attention" (S1). Besides, the students felt obliged to respond promptly to messages associated with their roles in organisations such as student societies (S4), part-time jobs (S6) or tutoring positions (S7). Further, some students acknowledged that they would respond to private chat messages directed to them (S8) or group chat messages "addressed specifically to me" (S3). At the other end of spectrum, they felt little need to respond to "meaningless gossip" (S10) and "conversations not related to me" (S7), especially those comprising "big group chat" (S5, S14).

Students' responses to external interruptions were heavily influenced by the task at hand or their level of engagement in learning activities that were underway. As mentioned earlier, students did on occasion choose to ignore notifications when they were occupied with learning tasks. Such instances of putting notifications temporarily aside were almost inevitably followed by delayed responses. That is, the students would typically respond to messages as soon as they reached a stoppable point in their learning task. S6 stated: "After I finished putting the ideas into words, I returned to take care of the messages immediately." On the other hand, when they were less engaged with the learning tasks at hand, they tended to respond to notifications more readily. S6 commented thus: "Usually I respond to messages immediately if I don't want to do the assignment or if it's boring or too confusing."

The students in the study were fully aware of the disruptive effects mobile phones might have on their study, and thus adjusted the location and accessibility of their phones in accordance with their need to concentrate. For example, S1 noted: "If I really need to concentrate, I will put my phone away. Otherwise, I will leave it within reach." S4 remarked that when he felt his mobile phone to be a constant distraction, he would turn 
it face down or put it out of sight. S6, the most frequent multitasker in the study, had a similar practice. She stated: "When I am under a deadline, I leave my phone in my room and study in the living room. I even disconnect WhatsApp on my laptop so no one can disturb me." Moreover, the students often enabled notification selectively in order to eliminate unnecessary alarms. For example, the students stated that WhatsApp allowed them to specify the chat groups from which they want to receive notifications. Hence, they could choose to mute the groups they were not quite attached to.

\section{Discussion}

This study explored multitasking with computers and mobile phones in a self-study context, with specific attention on the source of and responses to interruption. One revealing finding is the identification of task as an important dimension mediating both internal and external interruption, which contributes to a complex interplay between student, technology and task. This dovetails the multitasking metrics developed by Benbunan-Fich et al. (2011). In light of this, the following discussion of this study's findings will be structured along these three dimensions (Figure 1).

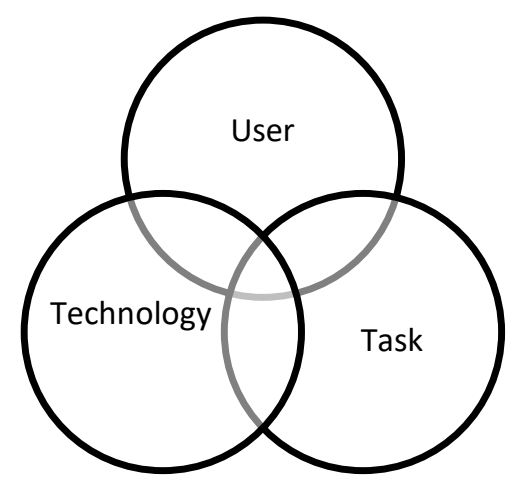

Figure 1. Framework of triggers for multitasking

\section{User-Task (UT)}

To a large extent, self-initiated interruptions are associated with the status, nature, and perception of the learning task in which students are engaged. As indicated by the observation data, task or subtask completion is a major trigger for task switching arising from within. This is in line with prior studies that indicated that people tended to switch tasks after sub-goal completion (Payne et al., 2007). Admittedly, such task switches can be considered a natural transition when a task finished (González \& Mark, 2005). However, the students in the study showed different perceptions in relation to what constitutes a sensible point for switching task. Another interesting finding is that some students tended to advance taking a break when they were close to completing a task.

In other scenarios, the students switched task when they were stuck, essentially putting the learning task on hold. This type of interruption might actually be beneficial, since such task switching can allow the learning problem to incubate, which could ultimately assist in arriving at a solution (Mark et al., 2005). On the other hand, in line with other studies (e.g., Qian \& Li, 2017), an easy task could also trigger multitasking for some students. Flow theory advanced by Csikszentmihalyi (1990) helps to shed a light on this phenomenon. Flow describes a state of complete immersion in a task, which can be seen as a polar opposite of the state of multitasking. According to Csikszentmihalyi (1990), a flow state involves a balance between task challenges and the person's skills. When tasks are perceived too challenging or too easy, a departure from flow state to multitasking is likely.

Additionally, congruent with previous work (e.g., Calderwood et al., 2014), this study noted a close association between task motivation and student multitasking behaviours. Task motivation is linked with several factors such as interest, perceived importance, and urgency of a task. Generally speaking, students tend to be more concentrated when working on something of interest to them, and when working to meet an imminent deadline. 


\section{Technology-User (TU)}

Hong Kong's mobile subscriber penetration rate of 237\% (Office of the Communications Authority, 2017) is one of the highest in the world. Further, a recent study among Hong Kong university students pinpointed mobile phones as the most used device in their daily lives (Deng, 2017). Many students in the study acknowledged habitually checking their phone constantly, or whenever they had time. While studying, they also usually kept their phone nearby so they could be aware of the arrival of notifications. This supports scholarly work that identified phone checking as habitual and impulsive behaviours that linked with multitasking (see Aagaard, 2015; Jin \& Dabbish, 2009; Wang \& Tchernev, 2012). Among the wide range of digital technologies the students were engaged with, IM is the most prominent and influential one. IM notifications have been identified as the main source of distraction in the study. IM notification is problematic not just because of its frequency, but also because it is more likely to prompt phone checking and responding.

\section{Technology-Task (TT)}

This study took both computers and mobile phones into account as the sources of interruption during selfstudy time. In general, mobile phones are the key source of interruption due to the fact that they are often designated for personal and leisure purposes, while laptops tend to be used more for academic purposes. Despite this, there are emerging signs of boundary crossing of devices in relation to learning-related practice. An increasing tendency of using mobile phone for academic work is in line with the noted growth of the phone as primary computing device (Karlson, Meyers, Jacobs, Johns, \& Kane, 2009), and increasingly blurred boundaries between work and home (Dearman \& Pierce, 2008).

\section{Technology-User-Task (TUT)}

When discussing external interruptions in the form of notifications, it becomes necessary to take a holistic stance by including user and task in the picture. Notifications or alerts from computers or mobile phones are interruptive technological mechanisms that prompt "transition and reallocation of attention focus" (McCrickard, Chewar, Somervell, \& Ndiwalana, 2003, p. 319). The students in the study showed a tendency to adjust their accessibility to mobile phones in accordance with the learning tasks at hand. When working to pressing deadlines or on important work, they consciously distanced themselves from the phone, thus eliminating the effects of interruption.

Furthermore, the students had different responses to notifications ranging from ignoring, previewing, reading message only, and responding to message. Students' reactions to external interruption are mediated by their ongoing learning tasks to a great extent. When deeply engrossed in their ongoing task, they became insensitive to external cues as noted in Miyata and Norman (1986). In some instances, there were lags between receiving notification and task switching. These are called interruption lags (Trafton et al., 2003) that indicate students exercising control over task switching until they have reached a sensible stopping point (e.g., finished one part of an assignment). Such delays in response entail an internal deliberation regarding whether and when to switch attention (Iqbal \& Horvitz, 2007). In this sense, the user is an active agent mediating to what extent the external interruption can actually cause distraction. In conclusion, how students react to external interruption is subject to the confluence of perceived importance, urgency, and the task currently being worked on.

\section{Conclusion}

This paper has revealed, in fine-grained detail, the complex and dynamic process of interruption of multitasking. The study started with the investigation into internal and external sources of interruption and sought to determine their association with multitasking. The results suggest that the dichotomy of internal and external interruption is problematic in that internal forces come into play in determining how a person reacts to external interruption, and that the influence of external interruption is subject to internal decision making. Internal and external interruptions actually intertwine in real-life multitasking scenarios. Based on the empirical evidence, the study advances a framework of triggers for multitasking that encompasses three interlinked dimensions: user, technology, and task. 
The findings of the study have several noteworthy implications for students, teachers, and researchers. Firstly, they could help students to better concentrate on study and mitigate the interruptions from within and outside. Awareness of the cost of off-task multitasking should be cultivated and suggestions on how to ward off the interruption should be shared with students. For example, students should be familiar with how to set notification and block unnecessary alarms. They should also be aware of the optimal timing for taking a break or switching tasks and try to avoid switching before completion of a task or subtask.

An important finding of the study is the identification of task as a critical element in mediating both internal and external drives for multitasking. This indicates that the teacher has a vital role when designing learning activities and tasks. As indicated by the data, students were likely to be engaged in off-task multitasking if they deem the tasks to be too difficult, too easy, or boring. Thus, at the top of the agenda for teachers should be aiming to design learning tasks that are meaningful, relevant, and give students a personalised learning experience with feedback. Lastly, the video-stimulated interviews involved in the study have been shown to be an effective way to capture the complicated motives for multitasking. It is hoped that the framework of the triggers for multitasking and the four reactive states to notification might also assist other researchers in conceptualising and designing studies in relation to multitasking.

\section{References}

Aagaard, J. (2015). Drawn to distraction: a qualitative study of off-task use of educational technology. Computers \& Education, 87, 90-97. https://doi.org/10.1016/j.compedu.2015.03.010

Adler, R. F., \& Benbunan-Fich, R. (2013). Self-interruptions in discretionary multitasking. Computers in Human Behavior, 29(4), 1441-1449. https://doi.org/10.1016/j.chb.2013.01.040

Adler, R. F., \& Benbunan-Fich, R. (2015). The effects of task difficulty and multitasking on performance. Interacting with Computers, 27(4), 430-439. https://doi.org/10.1093/iwc/iwu00

Bailey, B. P., \& Konstan, J. A. (2006). On the need for attention-aware systems: Measuring effects of interruption on task performance, error rate, and affective state. Computers in Human Behavior, 22(4), 685-708. https://doi.org/10.1016/j.chb.2005.12.009

Benbunan-Fich, R., Adler, R. F., \& Mavlanova, T. (2011). Measuring multitasking behavior with activity-based metrics. Transactions on Computer-Human Interaction, 18(2), Article 7. https://doi.org/10.1145/1970378.1970381

Calderwood, C., Ackerman, P. L., \& Conklin, E. M. (2014). What else do college students "do" while studying? An investigation of multitasking. Computers \& Education, 75, 19-29. https://doi.org/10.1016/j.compedu.2014.02.004

Calderwood, C., Green, J. D., Joy-Gaba, J. A., \& Moloney, J. M. (2016). Forecasting errors in student media multitasking during homework completion. Computers \& Education, 94, 37-48. https://doi.org/10.1016/j.compedu.2015.10.021

Csikszentmihalyi, M. (1990). Flow: The psychology of optimal performance. New York, NY: Harper and Row.

David, P., Kim, J.-H., Brickman, J. S., Ran, W., \& Curtis, C. M. (2015). Mobile phone distraction while studying. New Media \& Society, 17(10), 1661-1679. https://doi.org/10.1177/1461444814531692

Dearman, D., \& Pierce, J. S. (2008). It's on my other computer! computing with multiple devices. Proceedings of the Special Interest Group for Computer-Human Interaction Conference on Human factors in Computing Systems (pp. 767-776). Florence: Association for Computing Machinery.

Deng, L. (2017). Multitasking with ICT among University students: An exploratory study. In W. W. Ma, C.-K. Chan, K. Tong, H. Fung, \& C. W. R. Fong (Eds.), New Ecology for Education - Communication $X$ Learning (pp. 153-162). Singapore: Springer.

Dix, A., Ramduny-Ellis, D., \& Wilkinson, J. (2004). Trigger analysis: Understanding broken tasks. In D. Diaper, \& N. Stanton (Eds.), The handbook of task analysis for human-computer interaction (pp. 381400). Mahwah, NJ: Lawrence Erlbaum.

Gazzaley, A., \& Rosen, L. D. (2016). The distracted mind: Ancient brains in a high-tech world. Cambridge, MA: MIT Press.

Gerow, J. E., Galluch, P. S., \& Thatcher, J. B. (2010). To slack or not to slack: Internet usage in the classroom. Journal of Information Technology Theory and Application, 11(3), 5-24.

González, V. M., \& Mark, G. (2004). Constant, constant, multi-tasking craziness: managing multiple working spheres. Proceedings of the Special Interest Group for Computer-Human Interaction Conference on Human factors in Computing Systems (pp. 113-120). Vienna: Association for Computing Machinery. 
Hembrooke, H., \& Gay, G. (2003). The laptop and the lecture: The effects of multitasking in learning environments. Journal of Computing in Higher Education, 15(1), 46-64. https://doi.org/10.1007/BF02940852

Iqbal, S. T., \& Horvitz, E. (2007). Disruption and recovery of computing tasks: Field study, analysis, and directions. Proceedings of the Special Interest Group for Computer-Human Interaction Conference on Human Factors in Computing Systems (pp. 677-686). San Jose, CA: Association for Computing Machinery.

Jeong, S.-H., \& Fishbein, M. (2007). Predictors of multitasking with media: Media factors and audience factors. Media Psychology, 10(3), 364-384. https://doi.org/10.1080/15213260701532948

Jin, J., \& Dabbish, L. A. (2009). Self-interruption on the computer: A typology of discretionary task interleaving. Proceedings of the Special Interest Group for Computer-Human Interaction Conference on Human Factors in Computing Systems (pp. 1799-1808). Boston, MA: Association for Computing Machinery.

Judd, T. (2013). Making sense of multitasking: Key behaviours. Computers \& Education, 63, 358-367. https://doi.org/10.1016/j.compedu.2012.12.017

Judd, T. (2015). Task selection, task switching and multitasking during computer-based independent study. Australasian Journal of Educational Technology, 31(2). https://doi.org/10.14742/ajet.1992

Junco, R., \& Cotten, S. R. (2012). No A 4 U: The relationship between multitasking and academic performance. Computers \& Education, 59(2), 505-514. https://doi.org/10.1016/j.compedu.2011.12.023

Karlson, A. K., Meyers, B. R., Jacobs, A., Johns, P., \& Kane, S. K. (2009). Working overtime: Patterns of smartphone and PC usage in the day of an information worker. Galveston, TX: Springer.

Kraushaar, J. M., \& Novak, D. C. (2010). Examining the affects of student multitasking with laptops during the lecture. Journal of Information Systems Education, 21(2), 241-251.

Lin, L., Cranton, P., \& Lee, J. (2014). Research methodologies for multitasking studies. In V. C. X. Wang (Ed.), Handbook of research on scholarly publishing and research methods (pp. 329-348). Hershey, PA: IGI Global.

Lin, L., Mills, L. A., \& Ifenthaler, D. (2016). Collaboration, multi-tasking and problem solving performance in shared virtual spaces. Journal of Computing in Higher Education, 28(3), 344-357. https://doi.org/10.1007/s12528-016-9117-x

Lyle, J. (2003). Stimulated recall: A report on its use in naturalistic research. British Educational Research Journal, 29(6), 861-878. https://doi.org/10.1080/0141192032000137349

Mark, G., Gonzalez, V. M., \& Harris, J. (2005). No task left behind? Examining the nature of fragmented work. Proceedings of the Special Interest Group for Computer-Human Interaction Conference on Human Factors in Computing Systems (pp. 321-330). Portland, OR: Association for Computing Machinery.

McCrickard, D. S., Chewar, C. M., Somervell, J. P., \& Ndiwalana, A. (2003). A model for notification systems evaluation-assessing user goals for multitasking activity. Transactions on Computer-Human Interaction, 10(4), 312-338.

Miyata, Y., \& Norman, D. A. (1986). Psychological issues in support of multiple activities. In D. A. Norman, \& S. W. Draper (Eds.), User centered system design: New perspectives on human-computer interaction (pp. 265-284). Hillsdale, NJ: Lawrence Erlbaum.

Pashler, H. (1994). Dual-task interference in simple tasks: Data and theory. Psychological Bulletin, $116(2), 220-244$.

Patterson, M. C. (2017). A naturalistic investigation of media multitasking while studying and the effects on exam performance. Teaching of Psychology, 44(1), 51-57. https://doi.org/10.1177/0098628316677913

Paul, C. L., Komlodi, A., \& Lutters, W. (2015). Interruptive notifications in support of task management. International Journal of Human-Computer Studies, 79, 20-34. https://doi.org/10.1016/j.ijhcs.2015.02.001

Payne, S. J., Duggan, G. B., \& Neth, H. (2007). Discretionary task interleaving: Heuristics for time allocation in cognitive foraging. Journal of Experimental Psychology: General, 136(3), 370-388. http://dx.doi.org/10.1037/0096-3445.136.3.370Qian, Y., \& Li, L. (2017). Student off-task electronic multitasking predictors: Scale development and validation. Journal of the Scholarship of Teaching and Learning, 17(2), 53-73. https://doi.org/10.14434/josotl.v17i2.20682

Ravizza, S. M., Uitvlugt, M. G., \& Fenn, K. M. (2017). Logged in and zoned out: How laptop internet use relates to classroom learning. Psychological Science, 28(2), 171-180.

https://doi.org/10.1177/0956797616677314 
Rosen, L. D., Carrier, L. M., \& Cheever, N. A. (2013). Facebook and texting made me do it: Mediainduced task-switching while studying. Computers in Human Behavior, 29(3), 948-958. https://doi.org/10.1016/j.chb.2012.12.001

Salvucci, D. D., \& Taatgen, N. A. (2010). The multitasking mind. Oxford; NY: Oxford University Press.

Speier, C., Vessey, I., \& Valacich, J. S. (2003). The effects of interruptions, task complexity, and information presentation on computer-supported decision-making performance. Decision Sciences, 34(4), 771-797. https://doi.org/10.1111/j.1540-5414.2003.02292.x

Trafton, J. G., Altmann, E. M., Brock, D. P., \& Mintz, F. E. (2003). Preparing to resume an interrupted task: Effects of prospective goal encoding and retrospective rehearsal. International Journal of Human-Computer Studies, 58(5), 583-603. https://doi.org/10.1016/S1071-5819(03)00023-5

Walter, S. R., Dunsmuir, W. T., \& Westbrook, J. I. (2015). Studying interruptions and multitasking in situ: the untapped potential of quantitative observational studies. International Journal of HumanComputer Studies, 79, 118-125. https://doi.org/10.1016/j.ijhcs.2015.01.008

Wang, Z., \& Tchernev, J. M. (2012). The "myth" of media multitasking: Reciprocal dynamics of media multitasking, personal needs, and gratifications. Journal of Communication, 62(3), 493-513. https://doi.org/10.1111/j.1460-2466.2012.01641.x

Wood, E., \& Zivcakova, L. (2015). Understanding multimedia multitasking in educational settings. In L. D. Rosen, N. A. Cheever, \& L. M. Carrier (Eds.), The Wiley handbook of psychology, technology, and society (pp. 404-419). Malden, MA: Wiley Blackwell.

Wood, E., Zivcakova, L., Gentile, P., Archer, K., De Pasquale, D., \& Nosko, A. (2012). Examining the impact of off-task multi-tasking with technology on real-time classroom learning. Computers \& Education, 58, 365-374. https://doi.org/10.1016/j.compedu.2011.08.029

Zhang, W. (2015). Learning variables, in-class laptop multitasking and academic performance: A path analysis. Computers \& Education, 81, 82-88. https://doi.org/10.1016/j.compedu.2014.09.012

Zhang, W., \& Zhang, L. (2012). Explicating multitasking with computers: Gratifications and situations. Computers in Human Behavior, 28(5), 1883-1891. https://doi.org/10.1016/j.chb.2012.05.006

\section{Corresponding author: Liping Deng, lisadeng@hkbu.edu.hk}

Copyright: Articles published in the Australasian Journal of Educational Technology (AJET) are available under Creative Commons Attribution Non-Commercial No Derivatives Licence (CC BY-NC-ND 4.0). Authors retain copyright in their work and grant AJET right of first publication under CC BY-NC-ND 4.0.

Please cite as: Deng, L. (2020). Laptops and mobile phones at self-study time: Examining the mechanism behind interruption and multitasking. Australasian Journal of Educational Technology, 36(1), 55-67. https://doi.org/10.14742/ajet.5048 